\title{
Método de identificação do grau de gestão nas atividades de produção de flores de corte
}

\author{
Antonio Bliska Júnior; Antonio Carlos de O Ferraz
}

UNICAMP-FEA, Cidade Universitária Zeferino Vaz s/n, 13083-875 Campinas-SP; bliskajr@feagri.unicamp.br; carlos@feagri.unicamp.br

\begin{abstract}
RESUMO
A Floricultura é um dos mais importantes segmentos da agricultura brasileira, em função dos significativos recursos financeiros movimentados, do volume de mão-de-obra empregado e também pelo potencial de crescimento que possui, via incremento do consumo interno per capita e de exportação. Para tanto, questões como qualidade e gestão são fundamentais para que o setor se desenvolva e atinja esse potencial. O objetivo do trabalho foi desenvolver um método para os produtores identificarem, de maneira simples e rápida, o grau gerencial de suas atividades e adotarem fundamentos, critérios e práticas de gestão da qualidade que resultem na estruturação de seu negócio como uma empresa organizada. Os critérios preconizados pela Fundação Nacional da Qualidade foram adotados como linha mestra de seleção, priorização e hierarquização dos temas e indicadores gerenciais adotados no novo método. Dados primários e secundários coletados, priorizados e hierarquizados por meio da técnica Delphi constituíram os parâmetros de gestão da empresa agrícola. Para o Delphi, delineou-se um questionário, que foi aplicado a 41 especialistas do setor de flores, da iniciativa privada e de instituições públicas. Após a hierarquização, aqueles parâmetros foram convertidos em questões objetivas, utilizadas na elaboração de um segundo questionário, destinado à aplicação direta nas organizações envolvidas na atividade. Esse questionário, associado a uma tabela de pontuação, indica o grau de maturidade gerencial das organizações e aponta oportunidades de melhoria dos processos. A esse modelo deu-se o nome de Método de Identificação do Grau de Gestão (MIGG), aplicado a 14 organizações atuantes na floricultura brasileira. A consistência das respostas indicou que o método desenvolvido é adequado para identificar e avaliar o grau de gestão na produção de flores de forma rápida e a baixo custo.
\end{abstract}

Palavras-chave: Floricultura, qualidade, competitividade, agronegócio.

\author{
ABSTRACT \\ Management degree identification method in cut flowers \\ production activity
}

Floriculture is one of the most important segments of Brazilian agriculture due to the significant financial resources it involves, the amount of manpower employed and the potential for growth it presents through exportation and an increase of internal consumption. Therefore, quality and management are fundamental steps to make it grow. The objective of this paper was to develop a method to help producers of cut flowers in the task of identifying their managerial degree, leading them to adopt the theoretical basis, the criteria and activities of quality management that will result in an organized business. To develop this paper, the criteria recommended by the National Quality Foundation were used as a base line for the selection, the establishment of priorities and setting up of hierarchies of managerial themes and indicators to be adopted in the new method. Primary and secondary data, collected through this research, were given priorities and then hierarchy was set up through the Delphi technique in management parameters for agribusiness. A questionnaire was compiled and applied to 41 experts in the flower sector, both private and belonging to public institutions. Once set up the hierarchy of the parameters, these were converted into objective questions used to assemble a second questionnaire to be filled in by the organizations directly involved in the activity. This questionnaire, associated to a score table, indicates the managerial maturity degree of the organizations and points out the opportunities for process improvements. This model was called Management Degree Identification Method (MDIM). The MDIM was applied to 14 organizations involved in the Brazilian cut flower activity. The consistency in the answers obtained indicates that the method that was developed is adequate to quickly identify and evaluate the management degree in the production of cut flowers at a low cost.

Keywords: Floriculture, quality, competitivity, agribusiness.

(Recebido para publicação em 25 de agosto de 2011; aceito em 31 de julho de 2012)

(Received on August 25, 2011; accepted on July 31, 2012)

E $\mathrm{m}$ função dos significativos recursos financeiros movimentados e do volume de mão-de-obra empregado no setor de floricultura, este é considerado um dos mais importantes segmentos da agricultura brasileira e tem se expandido rapidamente (Anefalos, 2004). A atividade compreende desde a seleção genética de novas variedades e a produção de sementes e bulbos até a produção comercial de flores de corte, flores em vasos e plantas ornamentais para decoração e paisagismo (Castro, 1998). Em cada um desses processos, podem ser identificados diversos agentes, tais como fornecedores de insumos, produtores, cooperativas, transportadoras, exportadores, despachantes aduaneiros, representantes governamentais (brasileiros e estrangeiros), importadores, distribuidores, atacadistas, varejistas e consumidores finais (Anefalos, 2004).

O Censo Agropecuário de 1995-
1996, do Instituto Brasileiro de Geografia e Estatística (IBGE), base para um estudo mais aprofundado do próprio IBGE, em 2004, indicou que: 1) mais de 7.500 propriedades agrícolas declararam alguma receita com a venda de "flores e plantas ornamentais caracterizados como pequenos e médios produtores preponderantemente"; 2) quanto à receita, a floricultura obteve média 5,85 vezes maior que a obtida na maior parte 
dos demais estabelecimentos, o que demonstra seu grande potencial como negócio; 3 ) essa atividade tem forte apelo social, pois em áreas pequenas é possível obter receitas expressivas; 4) $15,6 \%$ dos proprietários eram, à época, associados a algum tipo de cooperativa e detiveram $13,80 \%$ a mais de renda que os não associados; 5) os produtores que utilizaram assistência técnica tiveram $25,53 \%$ a mais de receita do que aqueles que não foram assistidos; 6) no aspecto técnico, a receita foi 15,91\% menor dentre aqueles que não aplicaram fertilizantes; e 7) os 46,57\% com uso de irrigação, tiveram receita $61,86 \%$ superior aos demais (IBGE, 2004).

No Brasil, segundo Kiyuna (2009), o mercado interno não para de crescer, o que é positivo. Entretanto, o lado negativo é que, somado às oscilações cambiais, há um desestímulo à exportação, que representa uma força motriz importante da competitividade e qualidade para o setor, segundo Perosa (2003), Anefalos (2006) e Kiyuna (2009). Os principais entraves diagnosticados no Censo Agropecuário de 1995-1996, que ainda persistem, são reproduzidos a seguir: "Embora de modo geral bem estruturada, a floricultura nacional ainda apresenta deficiências organizacionais, com perdas de colheita e pós-colheita, embalagem, transporte e baixo índice de cooperativismo" (IBGE, 2004).

As flores de corte, devido às suas características intrínsecas de alta perecibilidade e diversidade de atributos desejáveis, tornam imprescindível a utilização de ferramentas de gestão para atender aos padrões de qualidade exigidos no mercado e, cada vez mais, elevados os períodos de durabilidade pós-colheita (BBH, 2005).

No Brasil a Fundação Nacional da Qualidade (FNQ) é, desde a sua fundação em 1991, uma das principais entidades responsáveis por disseminar os fundamentos da Excelência em Gestão para o aumento de competitividade das organizações e do Brasil. Embora possua diversas parcerias para abranger os mais variados setores econômicos e trabalhe em conjunto com o Serviço Brasileiro de Apoio às Micro e Pequenas Empresas (SEBRAE), além de já ter premiado empresas agríco- las no passado, a Fundação hoje não tem um trabalho focado para o setor de flores em particular (FNQ, 2009). O Modelo de Excelência em Gestão (MEG) e seus similares, como o Questionário de Autoavaliação MPE Brasil do SEBRAE, tem como características comuns a aplicação de procedimento de avaliação demorado e a necessidade de acompanhamento de consultores ou colaboradores previamente capacitados no processo. Tudo isso implica em um tempo longo de avaliação, muitas vezes meses, e custos elevados para obtenção dos resultados esperados. (SEBRAE, 2009; FNQ, 2009).

Kiyuna (2004) e IBGE (2004) indicam que a maioria das propriedades agrícolas produtoras de flores de corte ainda não segue uma prática empresarial. Revelam, ainda, que os números mostram as deficiências gerenciais do setor, quando analisam indicadores com baixos índices de escrituração agrícola, cooperativismo, informática, assistência técnica ou obtenção de financiamentos. Apesar da larga experiência técnica no cultivo de flores, resultado de anos de trabalho, a gestão do negócio frequentemente é intuitiva devido ao uso limitado de ferramentas de gestão.

Capacitar o produtor para assimilar e aplicar conceitos de competitividade, qualidade e gestão em substituição ao lucro simples é um desafio setorial. Essas deficiências foram apontadas pelo Ibraflor (2001), que à época, constatava ser necessário "viabilizar a floricultura como uma atividade agrícola sustentada no aspecto econômico-financeiro, e geradora de emprego e renda para promover a fixação do pequeno produtor no campo, por meio da atividade produtiva intensiva e que certamente contribuirá para se evitar o êxodo rural, ajudando a minimizar os problemas sociais nas grandes metrópoles", que aponta, ainda a necessidade de "capacitação gerencial dos produtores envolvidos na atividade", para que ultrapassem a fase de produção de sobrevivência, cresçam e se transformem em empresários com visão de mercado, atendendo melhor aos clientes, gerando empregos e renda em prol da sociedade e do país.

Segundo Castro, Cobbe \& Goeldert (1995), apud Tirado (2009), o gerencia- mento dos sistemas produtivos busca, em geral: 1) maximizar a produção biológica e/ou econômica; 2) minimizar custos; 3) maximizar a eficiência do sistema produtivo para determinado cenário socioeconômico; 4) atingir padrões específicos de qualidade; 5) proporcionar sustentabilidade ao sistema produtivo; 6) garantir competitividade ao produto. Considerando-se a competitividade do produto final, esse estudo abrange a necessidade das organizações se inserirem em um ambiente concorrencial. Ademais, a busca por padrões de qualidade evidencia a preocupação dessas mesmas organizações em satisfazer as necessidades do mercado consumidor, representado pelos clientes finais do sistema agroindustrial em análise: a floricultura de corte no Brasil.

Segundo estimativas da Câmara Setorial de Floricultura e do Ibraflor, 4 mil produtores em todo o Brasil dedicam-se à floricultura, a maior parte deles em propriedades com área média de cultivo de 1,5 hectare (Ibraflor, 2008). Desse total, 56\% fazem uso regular da escrituração agrícola, um dos parâmetros de gerenciamento utilizados na pesquisa do Ibraflor e avaliados por Kiyuna et al. (2004). Esses números, apesar de aparentemente discrepantes em relação ao censo do IBGE, consideram os produtores rurais que se dedicam à floricultura como sua principal atividade e principal fonte de renda, enquanto o IBGE computa todas as propriedades agrícolas que declaram algum tipo de receita com a venda de flores e plantas ornamentais. O índice de assistência técnica aos produtores é baixo, com $37 \%$ dos estabelecimentos atendidos, os quais apresentam menor produtividade, menor qualidade $\mathrm{e}$ menor renda em relação aos padrões de comercialização (IBGE, 2004). Como não houve mudanças substanciais nas políticas públicas setoriais nos últimos dez anos, como será visto na sequencia, há indicações de que a gestão da atividade agrícola, como negócio, está longe de seguir os melhores exemplos de administração utilizados nos demais segmentos da economia como indústria e prestação de serviços.

$\mathrm{Na}$ floricultura, em particular, a qualidade é uma preocupação antiga dos hibridadores, pois o lançamento de novas variedades deve prever as necessi- 
dades e preferências dos consumidores, tais como novas formas e cores, além de características agronômicas desejáveis, como resistência a doenças e alta produtividade. Essa preocupação ainda não se estendeu ao restante da cadeia produtiva. Uma grande oportunidade de fazê-lo, ou de iniciar o processo, ocorreu em 2000, com o lançamento do Padrão Ibraflor de Qualidade (Ibraflor, 2000), com apoio dos principais mercados de São Paulo, Paraná, Minas Gerais e Santa Catarina e, em 2001, com a criação do programa brasileiro de apoio às exportações, o Flora Brasilis (Ibraflor, 2001), liderado pelo Instituto Brasileiro de Floricultura (Ibraflor), em convênio com a Agência Brasileira de Promoção de Exportações e Investimentos (APEX). Ambos não atingiram os objetivos esperados. Hoje, o principal mercado formador de preços, o Veiling em Holambra, adota um sistema próprio de classificação e padronização (Veiling, 2009).

Os recentes resultados do mercado indicam queda dos valores exportados de flores, com clara perda de competitividade (Kiyuna et al., 2009), a qual não é percebida no mercado interno, onde os valores de consumo per capita de flores são baixos, porém ainda permitem ganhos aos produtores. Mas ao atender somente $\mathrm{o}$ mercado interno, menos exigente, a queda na qualidade é inevitável (Aki, 2009). Ademais, é limitada a capacidade de gestão de pequenos e médios produtores rurais no agronegócio de flores, em função do grande volume de informações técnico-administrativas que devem ser consideradas na tomada de decisões diárias, para planejamento no médio e longo prazo, devido à baixa capacitação dos produtores e de seus funcionários e da dificuldade de acesso a informações e novas tecnologias. Resulta daí sua perda de competitividade.

Frente a este cenário estabeleceram-se duas hipóteses. $\mathrm{H}_{1}$ : "A adoção de práticas de gestão, tais como escrituração, uso de assistência técnica e cooperativismo promove a redução do risco, agregação de valor, ganhos de competitividade e possibilidade de crescimento, principalmente aos micros, pequenos e médios produtores da cadeia de flores"; e $\mathrm{H}_{2}$ : "A identificação, por parte dos produtores, do estágio em que estão quanto ao grau de utilização de práticas modernas de gestão, vai auxiliar a transformar suas propriedades rurais e suas atividades agrícolas, em negócios estruturados e em organizações empresariais".

O objetivo deste trabalho foi desenvolver um método para que os produtores de flores de corte possam, de maneira simples e rápida, identificar o grau gerencial de suas atividades e possibilitar a adoção dos fundamentos, critérios e práticas de gestão da qualidade, que resultem na estruturação de seu negócio como uma empresa organizada. Os objetivos específicos foram: 1) identificar e hierarquizar parâmetros de gestão técnico-administrativa usual em propriedade rural voltada à produção de flores, independentemente de seu porte, nível tecnológico empregado no processo produtivo, ou localização geográfica; 2) desenvolver um procedimento auto-aplicável para que os produtores identifiquem o grau de gestão de seu negócio; 3) aperfeiçoar o método desenvolvido, mediante sua aplicação a um grupo de organizações ou empresas produtoras de flores de corte (teste de campo).

\section{MATERIAL E MÉTODOS}

Esse estudo foi realizado em quatro etapas principais. Na primeira, utilizouse a metodologia do Rapid Rural Appraisal ou simplesmente, RRA (Townsley, 1996) para levantamento de informações primárias quanto a aspectos de produção, como variedades cultivadas, nutrição, uso de agrotóxicos, fitossanidade, reciclagem de insumos e de restos culturais, colheita, póscolheita, embalagens e logística, bem como aspectos administrativos de recursos humanos, controle de custos, comercialização e financeiros, por exemplo.

Visando conhecer a realidade e as práticas de gestão na indústria de flores mundial, seus padrões de qualidade e competitividade, foram realizadas algumas pesquisas de campo fora do Brasil. As visitas compreenderam áreas de produção de flores de corte, como crisântemo e rosas; produção de sementes, de variedades floríferas diversas, em ambiente protegido, situadas na Guatemala (duas empresas), e Colômbia (três empresas e aeroporto de Bogotá). Incluíram ainda flores tropicais e folhagens na Costa Rica (duas empresas). Todos os cultivos situados em regiões produtoras eminentemente exportadoras, com destino a mercados exigentes como EUA e Europa. $\mathrm{Na}$ Colômbia, além da etapa de produção, visitou-se uma empresa de resfriamento rápido a vácuo das cargas de flores para exportação e acompanhou-se o processo de despacho e embarque no aeroporto de Bogotá (Bliska Júnior, 2005).

Em seguida, foi elaborado um roteiro de entrevista, para a aplicação de questionários estruturados, a informantes-chave, no Brasil, sobre o elo unidade de produção, com objetivo de caracterizar os sistemas produtivos predominantes e detectar os fatores limitantes do elo em questão. Procurou-se identificar diferenças nos modelos e estágios de gestão nas propriedades agrícolas produtoras de flores, concentrando-se as visitas nos municípios de Holambra e Atibaia, no estado de São Paulo, devido à importância como centro produtor, proximidade do centro consumidor e facilidade de acesso. As visitas de campo no Brasil totalizaram seis organizações: em Holambra, a Cooperativa Veiling, uma empresa de logística e três empresas produtoras de flores, e, em Atibaia, uma empresa produtora de flores. Além das visitas aos elos de produção, também foram feitas visitas e acompanhamentos de embarques de flores nos aeroportos de Viracopos, no município de Campinas, e no município de Guarulhos, na região metropolitana de São Paulo. As visitas no Brasil e no exterior, foram documentadas em relatórios contendo informações dos locais, cultivos e empresas e/ou organizações.

O levantamento de dados secundários, realizado através do Método de Coleta e Sistematização de Informações Secundárias (MECASIS) (Abipti, 1999), permitiu a identificação da grande variedade de ferramentas e parâmetros de gestão, técnicos e administrativos, relativos aos temas: gestão, qualidade, floricultura, cadeia de produção de flores, indústria de flores, flores de corte, competitividade, agregação de valor, padronização, rastreabilidade, certificação, comportamento do consumidor, 
comercialização de flores, mercado nacional e internacional, dentre outros temas relevantes para a pesquisa.

A partir das informações primárias e secundárias identificaram-se os fatores críticos para a cadeia de produção de flores, a serem confrontados com os critérios utilizados no Modelo de Excelência em Gestão (MEG) da FNQ e que serviram para a construção do Método de Investigação do Grau de Gestão (MIGG), em sua versão preliminar, constituído de um questionário aplicado a especialistas do setor, na

\section{Auto Avaliação \\ Gestão da Qualidade de Flores de Corte}

Nome da empresa:

Nome do respondente:

E-mail:

Tel: (

Data:

segunda etapa.

Utilizou-se a técnica Delphi (Wright \& Giovinazzo, 2000) para hierarquizar e selecionar parâmetros de avaliação do grau de gestão de empresas e/ou organizações agrícolas. Os procedimentos utilizados na elaboração no Delphi são descritos a seguir.

Primeiramente, a partir dos oito critérios de gestão da qualidade identificados pelo MEG da FNQ, ou seja, Liderança, Estratégias e Planos, Clientes, Informações e Conhecimento, Pessoas, Processos, Sociedade e Resultados, analisou-se a pertinência de sua manutenção como espinha dorsal do novo método a ser desenvolvido.

A partir da estrutura da FNQ, foram Este critério examina o processo de formulação das estratégias, enfatizando o planejamento, organização e o processo de implementação das estratégias.

\section{A- A organização possui um Plano de Negócio.}

$\operatorname{SIM}($ ) NÃO ( )

B-A organização possui em documento clara definição sobre sua razão de existir (o que fazer, qual sua finalidade - Missão) e aonde pretende chegar num futuro definido (Visão) e sobre os princípios organizacionais que orientam como os colaboradores (pessoas sob coordenação direta da empresa) devem agir no seu dia-a-dia (Valores).

$\operatorname{SIM}($ ) NÃO ( )

C- Existe um planejamento com etapas e metas definidas a serem cumpridas periodicamente (mensal, semestral ou anualmente).

SIM ( ) NÃO ( )

D- A organização trabalha com "índices de ajuste" de produção procurando adequar-se aos volumes de produtos demandados pelos clientes. SIM ( ) NÃO ( )

\section{Critério Liderança}

Este critério examina o sistema de liderança da organização e o comprometimento pessoal da direção no estabelecimento.

A- As relações entre colaboradores e superiores hierárquicos, entre a organização e seus fornecedores e entre a organização e seus clientes são harmoniosas?

$\operatorname{SIM}($ ) NÃO ( )

B- Não há atritos freqüentes e as reclamações são solucionadas rapidamente com a participação de todos os envolvidos?

SIM ( ) NÃO ( )

C- A administração comunica com freqüência e clareza os objetivos e resultados da organização?

SIM ( ) NÃO ( )

D- A administração procura se informar de todos os fatores, internos e externos, que influenciam os aspectos produtivos e comerciais da organização? SIM ( ) NÃO ( )

E-A administração toma a frente das principais ações e procura delegar adequadamente obrigações e responsabilidades aos demais funcionários?

$\operatorname{SIM}($ ) NÃO ( )

Tabela 1. Questionário de Autoavaliação - MIGG (self-evaluation questionnaire-MDIM). Campinas, Unicamp, 2010.

definidos os temas referentes a cada um dos oito critérios. Para tanto, foram utilizados os dados primários e secundários levantados na primeira etapa do estudo e considerados relevantes, pelo autor, para a atividade de produção de flores de corte. Obteve-se um total de 31 temas. Além disso, abriu-se a oportunidade aos especialistas para sugerirem a inclusão de outros temas, se os julgassem pertinentes.

Para cada um desses 31 temas foram selecionados indicadores, em números variáveis, em vista de sua relevância e complexidade, totalizando um universo de 156 indicadores. Adotou-se procedimento similar ao adotado na fase anterior, utilizando-se dados primários e secundários levantados na primeira etapa do estudo e permitindo aos especialistas sugerirem outros indicadores além dos já elencados.

Foram identificados e selecionados para participar do estudo, por meio de indicações de especialistas e através de busca e análise pormenorizada de currículos na Plataforma Lattes, 141 informantes-chave, ou especialistas, relacionados à cadeia produtiva da floricultura de corte: representantes de cooperativas, associação de classe, pesquisadores, extensionistas, engenheiros agrônomos, produtores de destaque na atividade e consultores dos principais pólos de produção do país.

Solicitou-se aos especialistas que priorizassem e hierarquizassem os critérios, temas e indicadores de gestão para o elo de produção, do MIGG de flores de 
corte. Em virtude de se trabalhar com um grupo de especialistas dispersos geograficamente, não foi possível realizar uma explanação presencial do projeto de pesquisa. Toda a comunicação foi feita através de correio eletrônico. A cada rodada da técnica Delphi, procurou-se incentivar os especialistas a emitirem sugestões para aperfeiçoamento do questionário. Além disso, a participação na pesquisa foi incentivada através de mensagens ou telefonemas.

Considerando-se o objetivo de elaboração de uma metodologia de rápida aplicação e fácil compreensão por parte dos produtores, o número de indicadores a serem escolhidos foi limitado a dois por tema. Apesar dessa limitação, a hierarquização definida no Delphi permitiu selecionar os indicadores mais relevantes em cada tema, de maneira a não comprometer a acuidade do MIGG.

Na terceira etapa do trabalho, gerou-se o Método de Identificação do Grau de Gestão (MIGG) da empresa rural propriamente dito, por meio da elaboração de um novo questionário. A avaliação por intermédio do MIGG, contida neste estudo, é organizada mediante a atribuição de pontos a cada parâmetro. Estes têm por correspondência uma questão no questionário a ser aplicado às organizações. Adotou-se o valor total de 1.000 pontos, sugerido também no MEG da FNQ, mas ponderados e distribuídos ao longo das questões deste estudo, em função dos resultados observados no processo de hierarquização dos critérios e temas realizados por meio da metodologia Delphi. Na pontuação foi considerada a hierarquização definida pelos especialistas para a atividade de

Tabela 2. Resultado final de Temas e Critérios do MIGG priorizados e hierarquizados segundo especialistas consultados pela metodologia Delphi (final result of hyerarchization of themes and criteria according to experts consulted through the Delphi technique of MDIM set up). Campinas, Unicamp, 2010.

\begin{tabular}{|c|c|c|c|c|c|}
\hline Critério & Posição & $\%$ & Rodada & Tema & Hierarquização \\
\hline \multirow{3}{*}{$\begin{array}{l}\text { Estratégias e } \\
\text { planos }\end{array}$} & \multirow{3}{*}{3} & \multirow{3}{*}{59,9} & \multirow{3}{*}{$3^{\mathrm{a}}$} & Formulação das estratégias & 1 \\
\hline & & & & \multirow{2}{*}{ Implementação de planos de ação } & 1 \\
\hline & & & & & 2 \\
\hline \multirow{2}{*}{ Liderança } & \multirow{2}{*}{7} & \multirow{2}{*}{52,9} & \multirow{2}{*}{$2^{\mathrm{a}}$} & Administração (governança) & 1 \\
\hline & & & & Exercício da liderança & 2 \\
\hline \multirow{3}{*}{ Clientes } & \multirow{3}{*}{4} & \multirow{3}{*}{48,5} & \multirow{3}{*}{$3^{\mathrm{a}}$} & Conhecimento de mercado & 1 \\
\hline & & & & Relacionamento & 2 \\
\hline & & & & Tratamento de reclamações e sugestões & 3 \\
\hline \multirow{3}{*}{ Sociedade } & \multirow{3}{*}{8} & \multirow{3}{*}{52,9} & \multirow{3}{*}{$2^{\mathrm{a}}$} & Responsabilidade ambiental & 1 \\
\hline & & & & Desenvolvimento social & 3 \\
\hline & & & & Responsabilidade social & 2 \\
\hline \multirow{3}{*}{$\begin{array}{l}\text { Informação e } \\
\text { conhecimento }\end{array}$} & \multirow{3}{*}{2} & \multirow{3}{*}{62,8} & \multirow{3}{*}{$3^{\mathrm{a}}$} & Informações da organização & 1 \\
\hline & & & & Informações comparativas & 2 \\
\hline & & & & Ativos intangíveis & 3 \\
\hline \multirow{3}{*}{ Pessoas } & \multirow{3}{*}{6} & \multirow{3}{*}{71,3} & \multirow{3}{*}{$3^{\mathrm{a}}$} & Qualidade de vida, higiene e segurança de trabalho & 2 \\
\hline & & & & Capacitação e treinamento & 1 \\
\hline & & & & Sistemas de trabalho & 3 \\
\hline \multirow{9}{*}{ Processos } & \multirow{9}{*}{5} & \multirow{9}{*}{51,3} & \multirow{9}{*}{$3^{\mathrm{a}}$} & Melhoramento Genético & 8 \\
\hline & & & & Plantio e Manejo & 1 \\
\hline & & & & Sanidade & 3 \\
\hline & & & & Nutrição & 2 \\
\hline & & & & Colheita e Embalagem & 4 \\
\hline & & & & Comercialização e Logística & 5 \\
\hline & & & & Manutenção & 9 \\
\hline & & & & Controle & 7 \\
\hline & & & & Financeiro & 6 \\
\hline \multirow{6}{*}{ Resultados } & & & & Econômico-Financeiro & 2 \\
\hline & & & & Clientes e Mercado & 1 \\
\hline & 1 & 64 & $\partial^{\mathrm{a}}$ & Sociedade & 5 \\
\hline & 1 & 64 & $2^{a}$ & Pessoas & 3 \\
\hline & & & & Processos & 4 \\
\hline & & & & Fornecedores & 6 \\
\hline
\end{tabular}


produção de flores de corte.

$\mathrm{Na}$ quarta etapa, aplicou-se o método proposto (MIGG) a produtores de flores de diferentes portes e regiões, para testar sua viabilidade de aplicação, especialmente quanto à compreensão e objetividade das questões, ao tempo de preenchimento e à sua aceitação. Também foi feita uma análise estatística dos resultados observados nesta etapa. O MIGG foi aplicado a 14 empresas e/ou produtores de flores de corte. A cooperativa Cooperflora, do município de Holambra, permitiu o convite aos produtores de rosas e flores silvestres a ela cooperados, para que se submeterem ao teste de autoavaliação. $\mathrm{Na}$ sede da cooperativa foi disponibilizada uma sala para apresentação dos conceitos de Gestão da Qualidade e dos objetivos da pesquisa, em três horários, ao longo do dia. Além disso, em evento técnico-científico, realizado em Campinas, com a participação de produtores de diversas localidades, foi aplicado o teste de autoavaliação àqueles que se dispuseram a participar da pesquisa após breve explanação. E uma empresa do Rio Grande do Sul foi avaliada via envio do questionário ao seu gestor, por correio eletrônico.
Para classificar as organizações, segundo o Grau de Gestão, é utilizado um gabarito para pontuar os questionários respondidos. Segundo as faixas de pontuação alcançadas, a organização é classificada em diferentes níveis, sendo possível avaliá-la pela descrição da maturidade da gestão do nível alcançado. A análise detalhada desse grau de maturidade possibilita a elaboração de uma análise organizacional minuciosa apontando as tendências positivas ou não da empresa.

\section{RESULTADOS E DISCUSSÃO}

Os resultados obtidos via metodologia Delphi permitiram hierarquizar os Critérios, Temas e Indicadores, de forma a se obter uma ferramenta de autoavaliação da Gestão da Qualidade de Flores de Corte bastante específica, do ponto de vista de sua aplicação agrícola. Ao mesmo tempo, em função da participação expressiva e acima da média, dos especialistas consultados, obteve-se uma visão ampla e imparcial das nuances da atividade. As consultas incluíram profissionais atuantes nas mais diversas áreas da floricultura, tais como fitopatologia, entomologia, fitotecnia, pós-colheita, cultivo protegido, meio-ambiente, engenharia de produção, administração e produção direta de flores de corte, gerando resultados consistentes, que tornaram o MIGG apropriado à aplicação no segmento de produção de flores.

Para obter consenso, priorizar e hierarquizar os critérios e os temas mais relevantes, foram utilizadas três rodadas de questionário Delphi, ao longo das quais 41 especialistas, dos 141 convidados, participaram do processo, representando $29,1 \%$, valor acima do número de participantes considerado na literatura como razoável para obtenção de resultados consistentes. Ao final da 3. a e última rodada do Delphi, todos os critérios, temas e indicadores pendentes das rodadas anteriores foram definidos, por consenso. Os temas e critérios são apresentados na tabela 2 .

O MIGG apresenta as seguintes vantagens, quando comparado aos modelos da FNQ (2009), do Prêmio de Competitividade da MPE (SEBRAE, 2009) e de outros autores: 1) simplicidade, pois, ao contrário dos demais, é elaborado apenas com perguntas diretas, com respostas "SIM" ou "NÃO", sem margens para dúvidas; 2) facilidade de

Tabela 3. Caracterização das empresas submetidas à avaliação da gestão da qualidade em flores (characterization of the companies evaluated for quality management in flowers). Campinas, Unicamp, 2010.

\begin{tabular}{|c|c|c|c|c|c|c|c|c|c|c|}
\hline Empresa & Municipio & $\mathbf{U F}$ & $\begin{array}{c}\text { Area } \\
\text { total (ha) }\end{array}$ & $\begin{array}{c}\text { Estufa } \\
\text { (ha) }\end{array}$ & $\begin{array}{c}\text { Campo } \\
\text { (ha) }\end{array}$ & $\begin{array}{l}\text { Colaboradores } \\
\text { administração }\end{array}$ & $\begin{array}{c}\text { Cultura } \\
1\end{array}$ & $\begin{array}{c}\text { Cultura } \\
2\end{array}$ & Pontos & Nivel \\
\hline 1 & Holambra & SP & 0,5 & 0,0 & 0,5 & 3,0 & Girassol & & 440 & 4 \\
\hline \multirow{3}{*}{2} & Holambra & SP & & & & & & & & \\
\hline & Andradas & MG & 40,0 & 35,0 & 2,0 & 400,0 & Rosa & & 645 & 6 \\
\hline & S. Benedito & $\mathrm{CE}$ & & & & & & & & \\
\hline 3 & Holambra & SP & 15,0 & & & 170,0 & Rosa & & 795 & 8 \\
\hline 4 & Holambra & SP & 43,0 & 6,0 & 6,0 & 74,0 & Rosa & Bulbo & 815 & 8 \\
\hline \multirow{2}{*}{5} & Holambra & $\mathrm{SP}$ & 300 & 190 & 40 & 2600 & Rosa & & 605 & 6 \\
\hline & Andradas & $\mathrm{MG}$ & & & & & & & & \\
\hline 6 & Holambra & SP & 10,0 & 1,7 & 0,0 & 23,0 & Lisianthus & & 630 & 6 \\
\hline 7 & Atibaia & SP & 11,0 & 10,0 & 0,0 & 60,0 & Rosa & Tango & 730 & 7 \\
\hline 8 & Holambra & SP & 50,0 & 12,0 & 4,0 & 60,0 & Crisantemo & Palmeiras & 805 & 8 \\
\hline 9 & Dois Irmãos & $\mathrm{RS}$ & 6,5 & 4,5 & 1,0 & 24,0 & Varias & & 560 & 6 \\
\hline 10 & Guararema & SP & 5,5 & 0,0 & 5,0 & 11,0 & Rosa & Girassol & 360 & 4 \\
\hline 11 & Guararema & SP & 4,8 & 0,0 & 2,4 & 4,0 & Aspargo & & 600 & 6 \\
\hline 12 & Paranapanema & SP & 16,0 & 6,5 & 8,5 & 100,0 & Rosa & Crisantemo & 770 & 8 \\
\hline 13 & Holambra & SP & 7,0 & 3,0 & 1,2 & 40,0 & Lirio & & 790 & 8 \\
\hline 14 & Holambra & SP & 7,0 & 3,5 & 0,0 & 56,0 & Hibiscus & Begonia & 890 & 9 \\
\hline
\end{tabular}


Tabela 4. Gabarito de pontuação do questionário de autoavaliação em gestão em flores de corte (feedback scores on self assesstment questionnaire on management of cut flowers). Campinas, Unicamp, 2010.

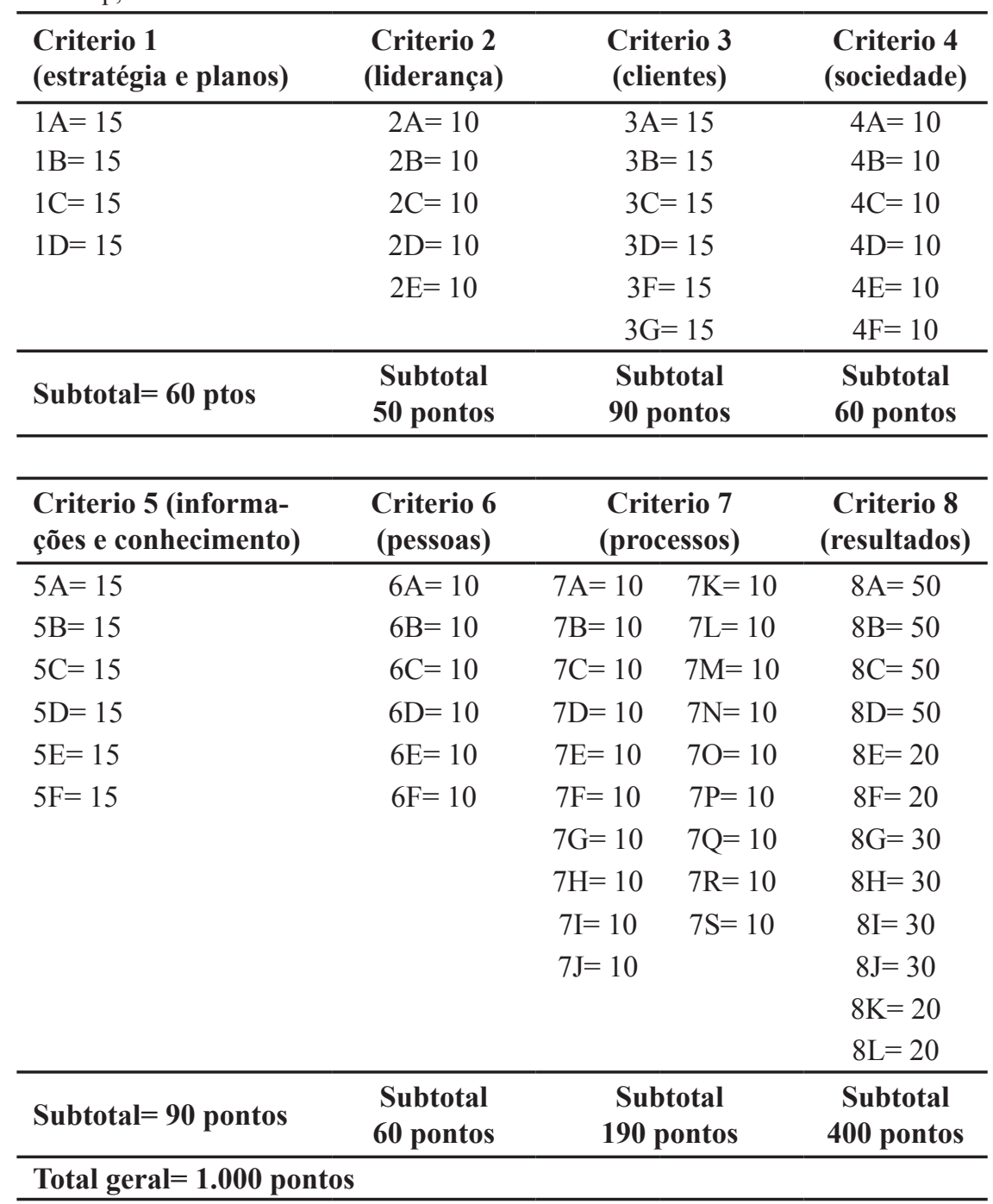

aplicação, pois os respondentes, mesmo sem profundos conhecimentos em gestão, podem utilizá-lo sem dificuldades; 3) rapidez no preenchimento do teste e obtenção da indicação do grau de maturidade da empresa; 4) baixo custo, pois no diagnóstico não são necessários pessoas, recursos financeiros e tempo significativo na elaboração de relatórios e planilhas; e 5) permite a análise, ainda que não exaustiva, dos pontos a serem melhorados quanto à gestão da qualidade (Bliska Júnior, 2010). Entretanto, o MIGG inclui somente dois indicadores por tema, portanto sua cobertura, em cada tema, é restrita. Lembramos que essa opção de utilização de somente dois indicadores por tema foi adotada nário referente à seleção dos indicadores econômico-financeiros. Por outro lado, especialistas da área econômica também tiveram dificuldades em selecionar indicadores técnicos. Essa mesma dificuldade é esperada junto aos produtores e administradores da organização, quando da aplicação do MIGG, devido à pouca familiaridade com alguns termos.

A partir da hierarquização de Critérios, Temas e Indicadores, obtida ao final da $3^{\text {a }}$ rodada Delphi, e de sugestões enviadas pelos especialistas, foi construído o questionário de avaliação do grau de maturidade em gestão, para aplicação em organizações que atuam na produção de flores de corte. Cada indicador correspondeu a uma questão, referente ao tema e critério ao qual estava associado, totalizando 61 questões. Ao final do processo, atendendo às sugestões recebidas quando o método foi testado junto a um grupo de 14 organizações (12 do segmento de flores de corte e duas do segmento de flores em vaso) chegou-se a um total de 64 questões. A aplicação do MIGG a duas organizações produtoras de vasos teve por objetivo avaliar sua adequação a este outro segmento da Floricultura e não interferiu nos resultados da pesquisa. Uma vez que os processos de produção e comercialização são idênticos nas duas modalidades de cultivo, flores de corte e vaso, não há diferenças nos indicadores usados no questionário. $\mathrm{O}$ mesmo raciocínio permitiu a utilização dos mesmos indicadores, e portanto do mesmo questionário, a diferentes espécies cultivadas, conforme mostrado na tabela 3.

Uma vez respondido o questionário, o mesmo é confrontado a um gabarito, apresentado na tabela 4 . Respostas positivas contam pontos e negativos somam zero, podendo atingir um máximo de 1000 pontos. A avaliação é feita com base na pontuação atingida, permitindo a classificação de cada organização segundo seu estágio de maturidade, em graduação crescente de 01 a 09 . A pontuação e a descrição dos níveis de gestão tomou por base o MEG-FNQ, que também adota um máximo de 1.000 pontos, e das priorizações e hierarquizações resultantes do questionário aplicados pela metodologia Delphi. A título de 
ilustração, na tabela 1 são apresentadas algumas questões do MIGG, balizadas nos indicadores selecionados na pesquisa Delphi. As hipóteses consideradas no estudo foram evidenciadas ao longo do trabalho, como mostram os resultados da tabela 3, de caracterização das empresas avaliadas pelo MIGG.

As fases preliminares desta pesquisa (RRA e MECASIS) forneceram os elementos para elaboração do questionário encaminhado aos especialistas, durante as rodadas Delphi, para que os critérios, temas e indicadores, diagnosticados como pontos críticos no processo de gestão da qualidade fossem priorizados e hierarquizados. Após três rodadas de aplicação do questionário, a priorização de indicadores, para obtenção do teste de autoavaliação, resultou na supressão de parte dos indicadores, pelos especialistas consultados. Estas sugestões e observações aportadas, quando compatibilizadas com o questionário original, encaminhado aos especialistas na primeira rodada Delphi, possibilitaram a elaboração de um Roteiro de implementação de conceitos de gestão da qualidade em flores de corte. Assim, foi possível atingir outro objetivo deste estudo, isto é, oferecer oportunidades para que as empresas possam adotar práticas de gestão visando à elevação contínua dos padrões de qualidade em todos os estágios do processo, da produção até a comercialização, conjugando o conhecimento dos produtores em sua atividade/ empresa e a expertise de especialistas do setor. Cada empresa pode elaborar seu plano de melhoria pela aferição dos pontos negativos levantados através do roteiro

O trabalho permitiu avaliar que o Método de Identificação do Grau de Gestão (MIGG):

Incorpora, no critério Processos, temas relevantes e característicos da produção agrícola, que o diferencia dos demais métodos.

É eficaz como método de autoavaliação nas atividades de produção de flores de corte para diagnosticar o grau de gestão de organizações de diferentes portes, ambientes, localizações geográficas e espécies produzidas.

É um método de baixo custo e rápida aplicação.

É eficaz em indicar caminhos de melhoria contínua da gestão da qualidade e oportunidades a serem exploradas pelas organizações, visando a redução do risco, agregação de valor e o aumento de sua competitividade.

\section{REFERÊNCIAS}

ABIPTI - Associação Brasileira das Instituições de Pesquisa Tecnológica. 1999. Agropolos: uma proposta metodológica. Brasília: ABIPTI/ SEBRAE. 375p.

AKI A. 2009. Boletim Flowerbusiness, semana 03 de 2009. Mensagem recebida por bliskajr@ feagri.unicamp.br .

ANEFALOS LC. 2004. Modelo insumo-produto como instrumento de avaliação econômica da cadeia de suprimentos: o caso da exportação de flores de corte. Piracicaba: USP-ESALQ. 210p (Tese doutorado).

ANEFALOS LC. 2006 Impactos das variações da taxa de câmbio na exportação brasileira de flores de corte: uma aplicação do modelo insumo-produto de processo. Agricultura em São Paulo 53: 123-139.

BBH - Blumen Bureau of Holland. 2005. Communication with the World Market of Flowers en Ornamental Plants, Apresentação PPT, Feira Hortitec, Holambra.

BLISKA JÚNIOR A. 2005. Relatório de Viagem. Campinas: Comitê Brasileiro de Desenvolvimento e Aplicação de Plásticos na Agricultura - COBAPLA, 6p.

BLISKA JÚNIOR A. 2010. Método de identificação do grau de gestão (MIGG) nas atividades de produção de flores de corte. Campinas: UNICAMP-FEAGRI. 163p (Tese doutorado).

CASTRO CEF. 1998. Cadeia produtiva de flores e plantas ornamentais. Revista Brasileira de
Horticultura Ornamental 4: 1-46.

FNQ - Fundação Nacional da Qualidade. 2009. Critérios de Excelência, São Paulo: FNQ. 52p.

IBRAFLOR - Instituto Brasileiro de Floricultura. 2000. Padrão Ibraflor de Qualidade. Campinas, $90 \mathrm{p}$.

IBRAFLOR - Instituto Brasileiro de Floricultura. 2001. Desenvolvimento e competitividade da floricultura brasileira. Relatório ao MAPA, Disponível em: www.ibraflor.com.br. Acessado em 30/9/09.

IBRAFLOR - Instituto Brasileiro de Floricultura. 2008. Floricultura no Brasil: Apontamentos mais relevantes sobre o papel sócio-econômico recente da atividade. Disponível em: www. ibraflor.com.br. Acessado em 30/9/09.

IBGE - Instituto Brasileiro de Geografia e Estatística. 2004. Caracterização do setor produtivo de flores e plantas ornamentais no Brasil. Rio de Janeiro: Estudos e Pesquisas, Informação Econômica, número 2. (CD-ROM)

KIYUNA I; FRANISCO VLFSF; COELHO PJ; CASER DV; ASSUMPÇÃO R; ÂNGELO JA. 2004. Floricultura brasileira no início do século XXI: o perfil do produtor. Informações Econômicas 34: 1-19.

KIYUNAI. 2009. Comércio exterior da floricultura em 2008: lições para o setor. Análises e Indicadores do Agronegocio 4 (3). Disponível em http://www.iea.sp.gov.br/out/LerTexto. php?codTexto=10164. Acessado em 30/9/09.

PEROSA JMY. 2003. Participação brasileira no mercado internacional de flores e plantas ornamentais. Revista Brasileira de Horticultura Ornamental 8: 1-11.

SEBRAE. 2009. Questionário de autovaliação MPE Brasil-Prêmio de competitividade para micro e pequenas empresas. São Paulo, 68p. Disponível em: www.sebrae.com.br. Acessado em: 25/10/2009.

TIRADO G. 2009. Demandas tecnológicas da cadeia da carne bovina: uma análise do Estado de São Paulo. Brasília: UNB-FAV. 170p. (Tese mestrado).

TOWNSLEY P. 1996. Rapid rural appraisal (RRA), Participatory rural appraisal (PRA) and aquaculture. Rome: FAO. 109p. (Fisheries Technical Paper, n.358)

VEILING. 2009. Critérios de padrão e qualidade. São Paulo. Disponível em: www.veiling.com. br. Acessado em: 25/10/2009

WRIGHT JTC; GIOVINAZZO RA. 2000. Delphi: uma ferramenta de apoio ao planejamento prospectivo. Caderno de Pesquisas em Administração 1: 54-65. 